\title{
Laser welding of polypropylene using two different sources
}

\author{
Chiara Mandolfino ${ }^{1, \text { a) }}$, Dermot Brabazon ${ }^{2, \text { b) }}$, Éanna McCarthy, ${ }^{2, c)}$, Enrico \\ Lertora $^{1, \mathrm{~d})}$, Carla Gambaro, ${ }^{1, \text { e) }}$, Inam Ul Ahad ${ }^{2, \text { f) }}$ \\ ${ }^{I}$ Department of Mechanical Engineering, Polytechnic School of University of Genoa, Via Opera Pia 15 \\ ${ }^{2}$ Department of Mechanical Engineering, University College Dublin, Belfield, Dublin 4, Ireland

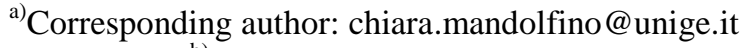 \\ b) dermot.brabazon@dcu.ie \\ c)eanna.mccarthy@dcu.ie \\ d)e.lertora@unige.it \\ e)gambaro@diptem.unige.it \\ f) inamul.ahad@dcu.ie
}

\begin{abstract}
In this paper, laser weldability of neutral polypropylene has been investigated using fibre and carbon dioxide lasers. A design of experiment (DoE) was conducted in order to establish the influence of the main working parameters on the welding strength of the two types of laser. The welded samples were characterized by carrying out visual and microscopic inspection for the welding morphology and cross-section, and by distinguishing the tensile strength.

The resulting weld quality was investigated by means of optical microscopy at weld cross-sections. The tensile strength of butt-welded materials was measured and compared to that of a corresponding bulk material.
\end{abstract}

\section{INTRODUCTION}

Polymers have been applied successfully in several industrial applications such as biomedical devices, microelectronic components, and transport industries. In particular, polyolefins are widely used due to many good properties such as low weight, mechanical and chemical resistance, machinability, and low production cost. When used for structural components, they may need to be joined because of production complexity or the requirement for function integration. Conventional plastic joining methods such as adhesives, fasteners, hot plate welding, and ultrasonic or vibration welding have been used, but they are often inadequate in the modern plastics industry [1,2]. Therefore, laser welding has become an established joining technology.

Compared to traditional joining technologies, the laser welding technique presents several advantages: high speed process, localized heat input to the joint interface without damaging the surrounding material or other nearby components by heat or residual stresses, reduced welding flash while maintaining part geometry, high quality in terms of good visual appearance as well as high mechanical strength, high degree of automation, perfect for a large range of sections starting from very thin sections due to the accurate control of the main processing parameters, the ability to weld materials with different colours including white materials, and ideal reproducibility.

Many papers in the literature report studies on Through-Transmission Welding, joining transparent to absorbent materials [3-7]. Indeed, in the past, butt-joint welding was considered inappropriate for industrial applications of laser welding of thermoplastic components. But due to the adaption of laser-beam absorption by suitable additives in the resin with economic concentrations, and new laser sources with wavelengths adapted to the absorption properties of the thermoplastic resin, butt-joint welding has become an interesting and viable alternative to weld thermoplastic components [1,8-12]. In particular, the development of near-infrared $2-\mu \mathrm{m}$ Tm-doped lasers has been driven by many applications in medical, commercial, and military technologies, and is now increasing its presence in the plastic industry. [11,12]. 
On the other hand, $\mathrm{CO}_{2}$ lasers (wavelength $=10.6 \mu \mathrm{m}$ ) are one of the typical radiation sources in infrared field welding, because most plastics would easily absorb the $\mathrm{CO}_{2}$ laser light. However, some studies report that the irradiated surface could be severely damaged due to the intense absorption of infrared radiation in the plastics [1].

This paper reports a comparison of welding tests performed using two different laser sources: a fibre laser and a $\mathrm{CO}_{2}$ laser. In particular, this study focused on the welding of polypropylene, in order to find the most suitable parameter setup with the laser system used.

\section{MATERIAL AND METHODS}

Two different laser sources were used to perform the same test campaign and set a comparison: a Tm-fibre laser (IPG Photonics TRL1904) installed on a robot arm (Panasonic TA1600) and a $\mathrm{CO}_{2}$ laser (Rofin DC 015). All the equipment is shown in Figure 1. Table 1 shows the detailed characteristics of the two laser sources.

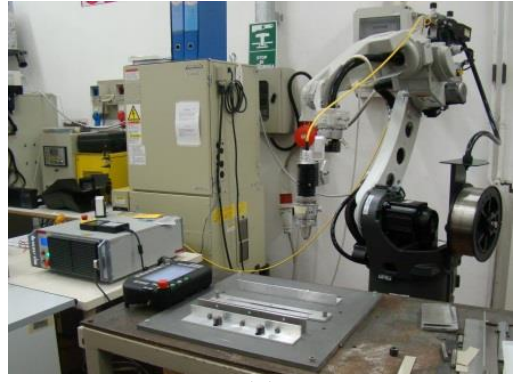

(a)

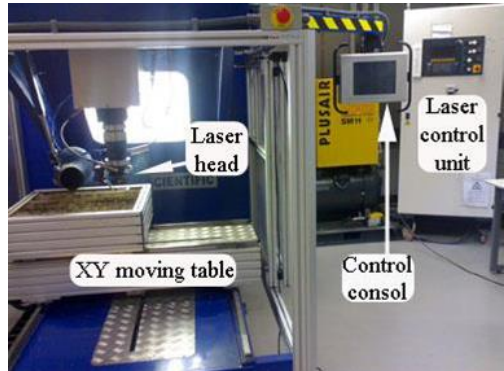

(b)

FIGURE 1. Laser sources: fibre laser (a) and $\mathrm{CO}_{2}$ laser (b)

TABLE 1. Laser system characteristics.

\begin{tabular}{lll}
\hline \multicolumn{1}{c}{ Fibre laser } & \\
\hline \multicolumn{1}{c}{ Characteristics } & \multicolumn{1}{c}{ Symbol /Value } & Unit \\
\hline Wavelength $\lambda$ & 1904 & $\mathrm{~nm}$ \\
Operating mode & Continuous wave modulation & \\
Nominal maximum power & 50 & $\mathrm{~W}$ \\
Power regulation & $10-100$ & $\%$ \\
Power stability & \pm 1 & $\%$ \\
Beam quality & TEM & \\
Fibre end & Collimator & \\
& & \\
\hline Wavelength $\lambda$ & 10.6 & $\mu \mathrm{m}$ \\
Operating mode & Continuous wave & $\mathrm{kW}$ \\
Nominal maximum power & 1.5 & $\%$ \\
Power regulation & $10-100$ & $\%$ \\
Power stability & \pm 2 & \\
Beam quality & TEM & \\
\hline
\end{tabular}

\section{Material}

The research focused on one polymer substrate, a polypropylene (PP) with no additives. Two samples, of dimensions $100 \times 25 \times 2 \mathrm{~mm}^{3}$, were welded together to realize each joint (Figure 2). Butt-welding experiments were performed, in which the laser radiation was focused directly on the interface between the parts, and the parts were pressed together. Appropriate sample holders were designed and assembled to ensure that a constant pressure was applied to the joining parts. 


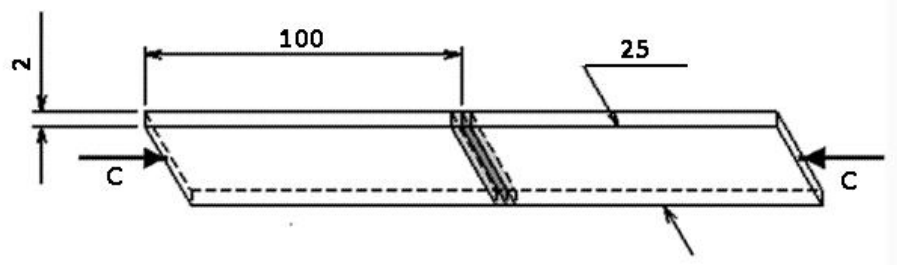

FIGURE 2. Joint sample

\section{Design of experiment}

To characterize the results of both laser sources, and to detect which factors affect the joint efficiency, an experimental plan was developed according to the Design of Experiment (DOE) technique. It was a $3^{3}$ full factorial design. This plan permits us to analyse the main factors, the two and three-factor interactions with no confounding. On the basis of background research activities on similar material and various references $[1,8,13]$, the following control factors were adopted: the irradiance $\left(\mathrm{I}=\right.$ Power / Spot Area), the residence time $\left(\mathrm{t}_{\mathrm{r}}\right)$, and the clamping pressure (C). Due to the differing power ranges, a larger spotsize was used with the $\mathrm{CO}_{2}$ laser to achieve the same irradiance. Higher scan speeds were used with this spotsize to keep the same residence time as for the fibre laser. For each set up, three replications were carried out. In Table 2, the adopted process conditions are summarised.

TABLE 2. Welding parameter set-up.

\begin{tabular}{cccccc}
\hline Control factors & Designation & Level 1 & Level 2 & Level 3 & Unit \\
\hline Irradiance & $\mathrm{I}$ & 3183.10 & 4456.34 & 5729.58 & $(\mathrm{~W} / \mathrm{mm})$ \\
Residence time & $\mathrm{t}_{\mathrm{r}}$ & 0.24 & 0.12 & 0.08 & $(\mathrm{~s})$ \\
Clamping pressure & $\mathrm{C}$ & 0.28 & 0.4 & 0.52 & $\left(\mathrm{~N} / \mathrm{mm}^{2}\right)$ \\
\hline
\end{tabular}

Mechanical characterization of the butt joints was carried out using an Instron Mod. 8802, referring to the UNI EN ISO 527 standard [14], at a constant speed of $5 \mathrm{~mm} / \mathrm{min}$; three samples for each parameter setup were tested and averaged.

\section{RESULTS AND DISCUSSION}

A macrographic inspection was performed in order to understand the influence of the setup parameters on the bead shape and to identify the depth of penetration.

In Figure 3 two examples of macrographs of butt joints realized with the different laser sources are shown.

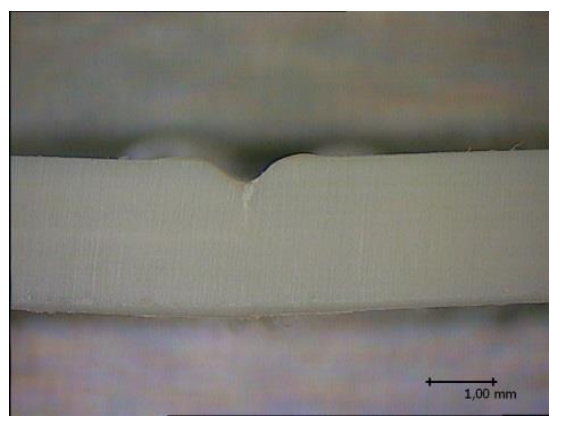

(a)

Fibre laser joint

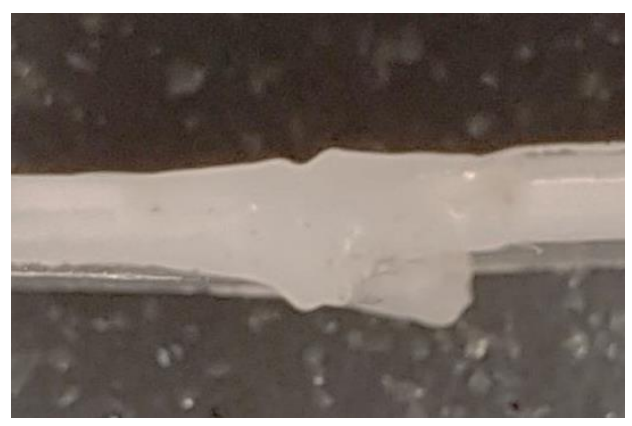

(b)

FIGURE 2. Macrographic analysis of joints realized with the different laser sources 
The polymer reveals a relatively high absorptivity at both wavelengths, enabling the melting of the material without adding any IR-light absorbers.

From the visual and macrographic inspection it is possible to state that an increase of the laser power results in an increase of the joint depth and width until the maximum depth (over the full sample thickness) and width are obtained. Increasing the power, the heat input also grew and produced a reduction of viscosity of the molten material. This behaviour implies that the material is "softened" over a certain period of time. Due to the force applied to the sample, the molten material is pressed out of the joining zone. The excessive material is transferred to the surfaces, and a bead is formed after re-solidification. The shape of the bead is defined by the re-solidification behaviour and viscosity of the material.

Tensile strength measurements were also performed on the welded samples to evaluate their mechanical strength and relate this characteristic with the parameter adopted.

A synthetic result is presented in figure 3, in which the maximum force registered during the tensile tests is associated to the irradiance and the residence time, keeping constant the clamping pressure in each graph.

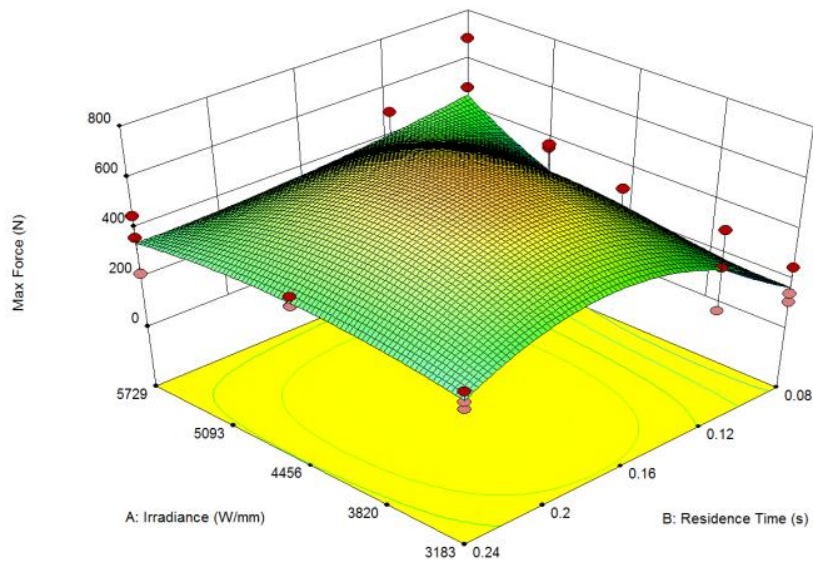

$\mathrm{CO}_{2}$ laser joint

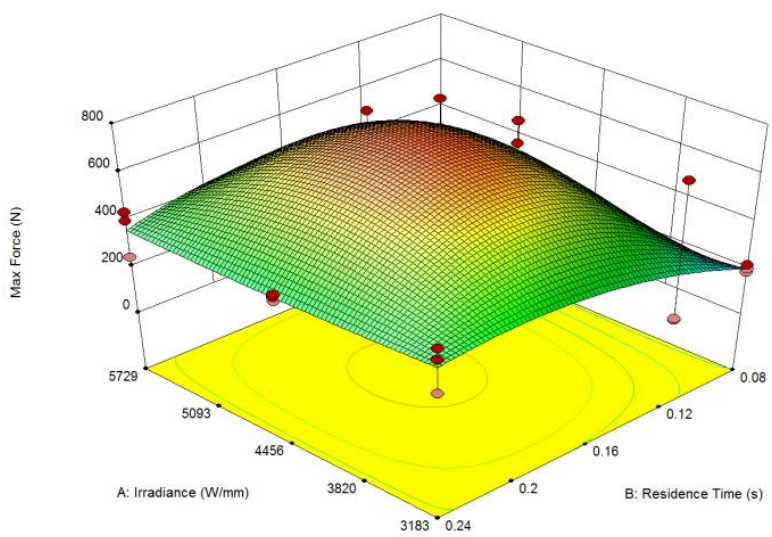

$\mathrm{CO}_{2}$ laser joint

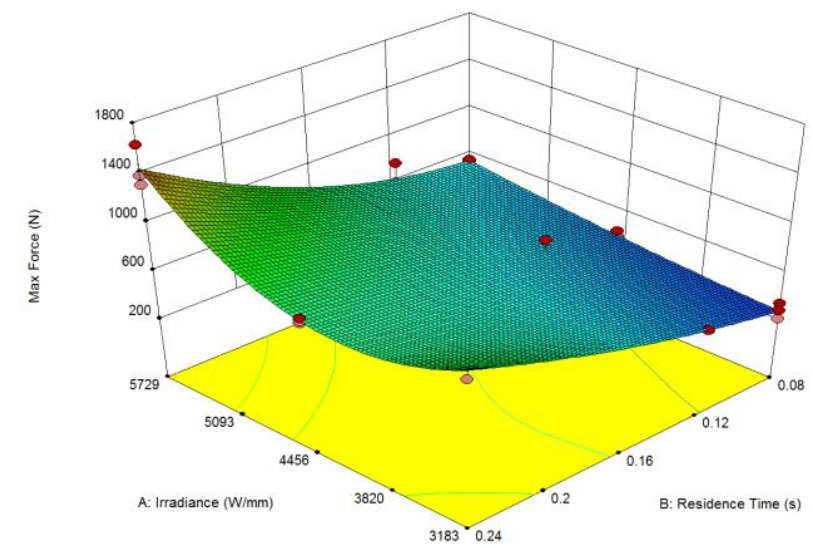

Fibre laser joint

(a)

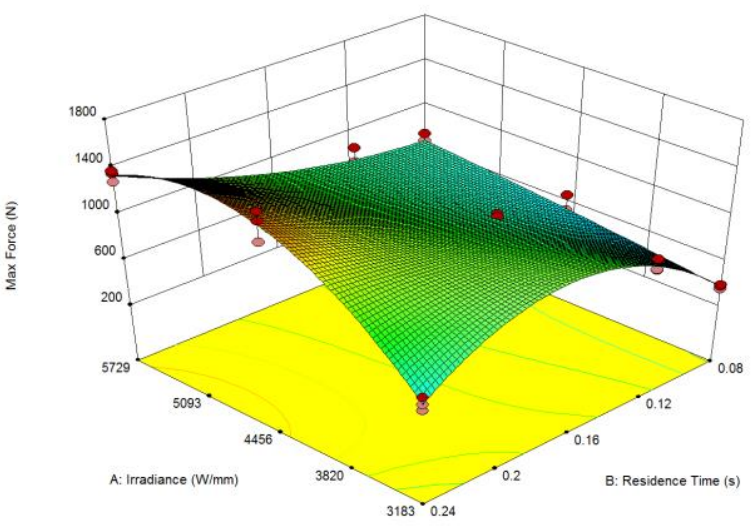

Fibre laser joint

(b) 


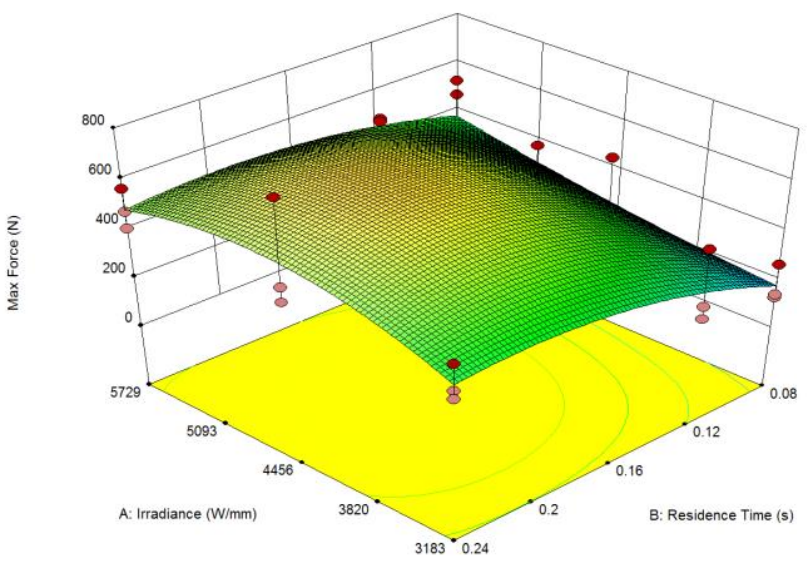

$\mathrm{CO}_{2}$ laser joint

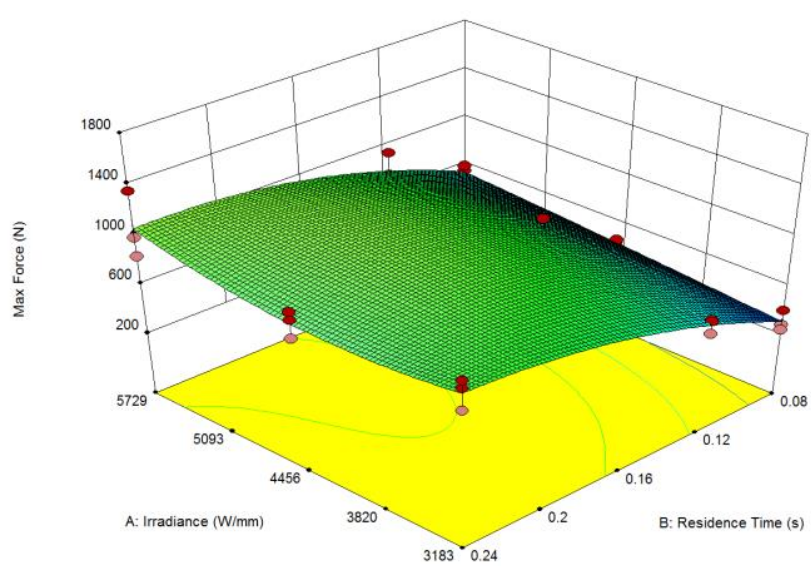

Fibre laser joint

(c)

FIGURE 3. Results of the mechanical characterization of the joints for the $\mathrm{CO}_{2}$ and the fibre laser sources at pressures of (a) $0.28 \mathrm{~N} / \mathrm{mm}^{2}$, (b) $0.4 \mathrm{~N} / \mathrm{mm}^{2}$, and (c) $0.52 \mathrm{~N} / \mathrm{mm}^{2}$

In order to understand the effect of the each parameter on the mechanical properties of the welded joints, Pearson correlation coefficients were calculated for both the test series and the results are reported in table 3 .

TABLE 3. Correlation coefficient.

\begin{tabular}{ccc} 
Control factors & $\mathbf{C O}_{\mathbf{2}}$ laser source & Fibre laser source \\
\hline Irradiance & 0.386 & 0.355 \\
Residence time & 0.390 & 0.773 \\
Clamping pressure & 0.116 & 0.049 \\
\hline
\end{tabular}

In both cases all the three parameters are proportional to the maximum force obtained by the tensile tests. Residence time, which is related to the travel speed, was the most significant. Irradiance, related to the power, is only slightly less significant than residence time in the case of $\mathrm{CO}_{2}$ laser welding, while is strongly less significant when a fibre laser source is used. The clamping pressure has a much lower significance in both cases.

\section{CONCLUSIONS}

A study on butt-welding of polypropylene with no absorbing additive was performed using laser radiation emitted by two different laser sources: a Tm-fibre laser operated at the wavelength of $2 \mu \mathrm{m}$ and a $\mathrm{CO}_{2}$ laser, using a DoE technique.

From the results, the main conclusions are the following:

- The polymer reveals a good absorptivity at both the wavelengths, enabling an efficient welding without adding any IR-light absorbers.

- Considering the correlation coefficient, the residence time, which is related to the travel speed, was the most significant parameter for both the laser sources. The clamping pressure has the lower significance in both cases.

- The efficient welding of the neutral polypropylene used in this study indicates the high absorptivity to both kind of laser beam and assures the ability to weld different colour plastics.

- The highly controlled processing parameters open the door widely for more advanced researches in welding thinner section. Moreover, provide the ability for the internal melting or ablation in thicker sections without harming the outer surface by concentrating the thermal energy required for melting in a specific location 
inside the part while the defocused beam coincides on the surface carries lower energy density than that needed for melting.

\section{ACKNOWLEDGMENTS}

The authors would like to thank the funding agency Enterprise Ireland for funding this work under grant $\mathrm{CF} / 2014 / 2619$.

The authors also acknowledge for the support IPG Photonics Italy, which provided the fibre laser source and the experience of its specialists.

\section{REFERENCES}

1. R. Klein, Laser Welding of Plastic, (Wiley-VCH Verlag \& Co. KGaA, Weinheim, Germany, 2012)

2. T. Brokholm Juhl*, D. Bach, Ronald G. Larson, J. de Claville Christiansen, E. Appel Jensen, Predicting the laser weldability of dissimilar polymers, Polymer 54 (2013) 3891-3897.

3. V. Wippo, P. Jaeschke, M. Brueggmann, O. Suttmann, L. Overmeyer, Advanced laser transmission welding strategies for fibre reinforced thermoplastics, Physics Procedia 56 ( 2014 ) 1191 - 1197.

4. V. Mamuschkin, A. Roesner, M. Aden, Laser transmission welding of white thermoplastics with adapted wavelengths, Physics Procedia 41 ( 2013 ) 172 - 179.

5. T. Brokholm Juhl*, J. de Claville Christiansen, E. Appel Jensen, Mechanical testing of polystyrene/polystyrene laser welds, Polymer Testing 32 (2013) 475-481.

6. A. Roesner, S. Scheik, A. Olowinsky, A. Gillner, U.Reisgen, M. Schleser, Laser Assisted Joining of Plastic Metal Hybrids, Physics Procedia 12 (2011) 370-377.

7. F.Cornacchia, A. Toncelli, M.Tonelli, 2- $\mu$ m lasers with fluoride crystals: Research and development, Progress in Quantum Electronics 33 (2009) 61-109.

8. I. Mingareev, F. Weirauch, A. Olowinsky, L. Shah, P. Kadwani, M. Richardson, Welding of polymers using a 2 um thulium fiber laser, Optics \&Laser Technology 44 (2012) 2095-2099.

9. A. Godard, Infrared (2-12 $\mu \mathrm{m})$ solid-state laser sources: a review, C. R. Physique 8 (2007) 1100-1128.

10. Hemming, N. Simakov, J. Haub, A. Carter, A review of recent progress in holmium-doped silica fibre sources, Optical Fiber Technology, in press.

11. C.W. Rudy, M.J.F. Digonnet, R.L. Byer, Advances in 2-lm Tm-doped mode-locked fiber lasers, Optical Fiber Technology, in press.

12. W. Romanowski, R. Lisiecki, H. Jelinkov, J. Sulc, Thulium-doped vanadate crystals: Growth, spectroscopy and laser performance, Progress in Quantum Electronics 35 (2011) 109-157.

13. C.Mandolfino, E.Lertora, C.Gambaro, Neutral polypropylene laser welding, AIP Conference Proceedings Volume 1769, 19 October 2016, Article number 100002

14. UNI EN ISO 527-1:2012. Materie plastiche - Determinazione delle proprietà a trazione - Parte 1: Principi generali. 